\title{
Bridging the Macro and the Micro by Considering the Meso: Reflections on the Fractal Nature of Resilience
}

\author{
$\underline{\text { Johan Bergström }}^{1,2,3}$ and Sidney W. A. Dekker ${ }^{4,5}$
}

\begin{abstract}
We pursued the following three interconnected points: (1) there are unexplored opportunities for resilience scholars from different disciplines to cross-inspire and inform, (2) a systems perspective may enhance understanding of human resilience in health and social settings, and (3) resilience is often considered to be fractal, i.e., a phenomenon with recognizable or recurring features at a variety of scales. Following a consideration of resilience from a systems perspective, we explain how resilience can, for analytic purposes, be constructed at four scales: micro, meso, macro, and cross-scale. Adding to the cross-scale perspective of the social-ecological field, we have suggested an analytical framework for resilience studies of the health field, which incorporates holism and complexity by embracing an ecological model of cognition, something supported by empirical studies of organizations in crisis situations at various spatial as well as temporal scales.
\end{abstract}

Key Words: human resilience; organizational resilience; resilience; resilience engineering; societal resilience

\section{INTRODUCTION}

The growing interest in resilience in the health sciences is part of a broader and multidisciplinary appreciation for resilience as a metaphor, theory, set of capacities, and even a strategy (Norris et al. 2008). For a special issue of this kind it is therefore appropriate to consider D. E. Alexander's challenging remark that "it is striking how the term is used in different disciplines without any reference to how it is employed in other fields, as if there were nothing to learn or transfer from one branch of science to another" (Alexander 2013:1281). The point would be to identify, and get inspired by, commonalities and differences in the theoretical and practical use of resilience in multiple disciplines. We hope that we might be able to introduce some 'epistemological pluralism' (Healy 2003) to the field by discussing the construction of resilience in different fields of research. Although this special issue focuses on resilience as constructed in the health sciences, we hope that our suggested analytical framework will also serve as inspiration to future social-ecological studies.

We focused on Gunderson and Holling's idea that "resilient systems can be as small as a family or as large as a nation " (2002:107), i.e., the idea of resilience being fractal, a phenomenon with recognizable or recurring features at a variety of spatial scales. We have resisted a classic systems theoryapproach of analytically drawing the boundaries of the 'system. ' Rather, we focused on the construction of resilience, and how it differs or shows commonalities depending on the level of resolution of the study. Do health scientists construct resilience in the same way as the scientists interested in organizational, community, or societal resilience? The topic of this special issue, human resilience in the context of interconnected health and social systems, in itself suggests the need for understanding system behavior at different aggregation levels, i.e., the human, the health and social system, and the interconnections of multiple health and social systems, to generate convincing answers.

We introduce a construction of resilience based on some central holistic principles of complexity theory and then review how resilience gets constructed in health science, studies of organizational resilience, studies of societal resilience policy, and finally the cross-scale studies of social-ecology. We argue that although studies of human resilience at various scales have a tendency to, in a reductionist manner, locate the subject of study at the level of the individual psychosocial actor, the field could find additional inspiration from studies at the meso level. Although such inspiration is indeed found in the social-ecological field of research, we aim to contribute to the analytical toolbox of health resilience research, hopefully with implications for other readers of the journal, through the introduction of models of cognition as emergent systems property. We also suggest the need to not only consider resilience across spatial but also temporal scales.

\section{RESILIENCE AS AN EMERGENT SYSTEM PROPERTY}

We do not intend to make this into a historical, or archaeological, overview of resilience theories. When it comes to defining resilience in different academic schools there are already a number of well-written reviews on the topic (see for instance Alexander's (2013) etymological journey, Kolar's (2011) overview of the historical development, Norris et al.'s (2008) presentation of resilience as a coherent theory drawing on several disciplines, or Walker and Cooper's (2011) genealogical account of resilience in the security field). Defining in all theories of resilience, being it a mechanical stress-strain model, a psychological model, a model of health, an organizational contingency theory, or a theory of a resilient society, is the capacity to absorb and/or adapt to disturbance or stress. Further, most studies of resilience motivate the focus on resilience by the complexity of the system (Holling 1973, Walker et al. 2004, Hollnagel et al. 2006a, Woods and Wrethall 2008, Nemeth et al. 2011, Woods and Branlat 2011, Alexander 2013), however rarely with further elaboration of what such an assumption implies. Rooted in complexity theory is the idea that resilience is a system property, emerging from interactions and relations at local levels.

\section{The principle of emergence}

The principle of emergence, as defined by complexity theory, implies that the macrobehavior of the system emerges from

${ }^{1}$ Lund University Centre for Societal Resilience, ${ }^{2}$ Lund University Centre for Risk Assessment and Management (LUCRAM), ${ }^{3}$ Lund University Division of Risk Management and Societal Safety, ${ }^{4}$ Safety Science Innovation Lab - School of Humanities, Griffith University, ${ }^{5}$ University of Queensland 
microbehavior, but not through direct control. The principle is based on the central tenet of general systems theory, which states that the behavior of the whole is not reducible to the behavior of the constituent components or actors (Von Bertalanffy 1950, Heylighen et al. 2007). With regard to analysis of the emergent behavior of the whole, complexity theory asks students of complex systems to turn their focus toward interactions and relationships, i.e., the 'local' interactions, which influence the behavior of the whole.

\section{The principle of locality}

The locality principle implies that all actions in a complex system are local. What each actor in the complex system does makes sense under the local conditions in which the actor operates, but the actor is unable to know the full effects of his actions. Actors respond locally to local information regarding locally changing conditions by adapting their coping strategies within an inherently uncertain environment. There is no single actor with knowledge of the entire complexity of the whole system, because that would imply the paradox of that actor needing to be as complex as the system itself (Cilliers 1998, Dekker 2011). The locality principle implies that each actor in a complex system controls little, but influences everything. No single actor guarantees the emergent resilience of the whole, but all actors influence the resilience of the whole through their local actions, relations, and interactions.

\section{The openness of the resilient system}

Just like general systems theory, complexity theory suggests that any attempt to draw a boundary around a complex system will represent an analytical sacrifice made by the one drawing it. Complex systems typically interact with their environment, and pressures from the surroundings affect the local adaptive strategies used by the system's actors. In Cilliers' words, "because complex systems are open systems, we need to understand the system's complete environment before we can understand the system, and, of course, the environment is complex in itself. There is no human way of doing this" (Cilliers 2005:258).

The above three principles of complexity imply that whether we target the analysis of resilience on the human, the organization, the community, or the society, drawing boundaries around the system will always be an analytical sacrifice. They are all open systems. The answer to the question of 'where' resilience emerges should then be that it is a matter of where the boundaries are drawn.

\section{RESILIENCE AT DIFFERENT SPATIAL SCALES}

Before theorizing about the notion of resilience in different spatial scales, it should be repeated that any resilient system requires a threat, i.e., a stressor, danger, disturbance, or crisis. In fact, it seems impossible to define anything as resilient without something threatening its existence, functioning, or survival, at whatever level of intensity. For each of the three spatial scales introduced, we will try to describe the kinds of threats that typically form the starting point of resilience studies. We will also discuss how the notion of danger as a prerequisite, or even raison d'être of the resilient subject, can be turned into a critique of resilience theory.

\section{Micro: human resilience}

For health scientists starting to deal with resilience theory, resilience typically emerges at the level of the psychosocial subject (Ungar 2005, Kolar 2011, Aranda et al. 2012, Alexander 2013).
The threat to the resilience of the psychosocial subject is adversity, manifested by stressors such as poverty, psychopathology, and trauma. The ability to be resilient is the ability of the human subject to thrive despite such stressors. Some groups might be identified as more resilient, i.e., coping or ending up in chronic illness, than others (the dependent variable) by randomized groups experiencing the same kinds of adversities (the controlled variable; Allmark et al. 2014).

Although such an approach might seem reductionist in its isolation of the resilient capability at the level of the human mind, rather than considering the relationships between subjects and the adversities they face, there is an on-going discussion in this field that suggests a more holistic view on the subject. Luthar and Cicchetti (2000:858) defined resilience as a "two-dimensional construct that implies exposure to adversity and the manifestation of positive adjustment outcomes,"emphasizing that vulnerability, as well as protective factors, can each derive from multiple levels, such as the community, the family, and the individual. Aranda et al. (2012) offered an interesting discussion examining the subject from three different narratives of resilience: as found, as made, and as unfinished. They argued for a need to broaden the perspective to include interactions and relationships with the construction of the resilient subject.

Health and social care practitioners are often reminded of the need to recognize and value otherness, for example in their ethical practices or through professional codes (Aranda and Jones 2010), but rarely are they encouraged to recognize the relatedness and connectivity to the other, and what is, as Butler (2004) argued, our shared vulnerability and dependence (Aranda et al. 2012).

Other interdisciplinary studies have also emphasized the importance of understanding human resilience, not in terms of self-contained individuals but by emphasis on the context, suggesting that human resilience indeed can be constructed in terms of relationships between human subjects and contextual factors, i.e., an approach rooted in the complexity principles introduced (Almedom 2004, Almedom and Glandon 2007, Hamiel et al. 2013). This seems to be the result of the introduction of the human ecological theory into resilience studies, typically focusing on the interactions between individuals and their environment (Kolar 2011).

\section{Meso: resilient organizations}

One academic community interested in the studies of resilient organizations is a branch of the so-called Safety Science. Originating in studies of accidents in high-risk socio-technical organizations, including, e.g., aviation, nuclear power, shipping, mining, and off-shore drilling, Safety Science is dedicated to understanding how accidents emerge from organizational processes at different levels, i.e., operator behavior, team performance, management decisions, and organizational culture. The focus on organizational resilience was suggested some 10 years ago by a few authorities in the field to form a collective of researchers dedicated to study of not so much why things go wrong but rather why things go right despite the complexities, goal conflicts, time pressures, and needs for constant trade-offs (Rasmussen 1997, Hollnagel 2009) at all levels of the organization. Four anthologies on the topic of 'resilience engineering,' the defining label of the field, have been published since 2006, and a fifth one is in press. 
The threat, which forms the prerequisite for a need to be resilient, to scholars of the Safety Science, is the clear link between system complexity and physical danger, resulting in accidents; a view contributed to the field by Perrow 30 years ago (Perrow 1984). To scholars within the resilience engineering community, this complexity is inherent in the normal day-to-day operation of the system: "there are no special error producing processes that magically begin to work when an accident is going to happen but which otherwise lie dormant. On the contrary, there are no fundamental differences between performance that leads to failures and performance that leads to successes" (Hollnagel 2008: xxxv).

Emphasizing the challenge of resilience to cope with ordinary system variability, interpreted as the result of system complexity, the focus in most resilience engineering studies is on the system's adaptive capacity, i.e., "the ability to adjust its functioning" (Hollnagel 2008:xxvii). The focus on adaptive capacity is rooted in a system dynamics model (Rasmussen 1997), efforts to make an analogy between the system dynamics model and a more mechanical stress-strain model (Woods and Wrethall 2008), or on Hollnagel's early (Hollnagel 2006, Hollnagel et al. 2006b) or more recent (Hollnagel 2008) definitions emphasizing the ability to adjust system functioning prior to and following disturbance.

In theorizing resilient organizations, scholars of resilience engineering seem to construct the location of resilience at the emergent level of the organization in accordance with the holistic principles outlined above (Costella et al. 2009, Carmeli et al. 2013). However, when actually conducting studies the empirical focus often seems to be on the individual operators, the activities that they engage in (Nemeth et al. 2007, 2011, Patterson et al. 2007, Gomes et al. 2009, Grote et al. 2009, Ross et al. 2014), or the skills that they have (Morel et al. 2008, 2009, Re and Macchi 2010). Although some studies seem to simply move the subject of resilience from the sharp end operators to the blunt end managers (Miller and Xiao 2007, Paltrinieri et al. 2012, Carmeli et al. 2013), others do address connections between different organizational levels to understand or improve resilience. Saurin and Carim Júnior (2011) reported from the development and testing of a resilience auditing framework addressing the individual, the team, and the organizational level. Aiming to enhance system resilience, Johnsen and Veen (2013) also suggested interventions at several organizational levels.

Our discussion introduces some additional ideas for how studies of the meso level might both bridge and inspire resilience research at the micro and macro levels.

\section{Macro: societal resilience}

The field, which by its name seems to have adopted the greatest macro focus, should be the one focusing on policy making with an aim to establish resilient societies. This might also be the most diverse field of the three introduced. The defining discipline of the field seems to be the science of social-ecological systems, with its heritage in the resilience notion from ecosystems science (Walker and Cooper 2011, Alexander 2013). Although the field also includes engineering studies of resilient infrastructure networks (McDaniels et al. 2008, Cimellaro et al. 2013), or action research frameworks dedicated to capacity development of communities and societies (Becker et al. 2011), there is also a branch clearly positioned in the health sciences (Gibbs et al. 2013,
Hamiel et al. 2013, O'Sullivan et al. 2013). The threats forming a coherent rationale behind most studies of societal resilience are (1) natural disasters or (2) antagonistic acts to which the system needs to adapt without changing its form (Gunderson and Holling 2002).

The field of societal resilience is currently reaching national and international policy agendas. Following events such as the 9/11 attacks, the tsunami of southeast Asia in 2004, and hurricane Katrina, the focus, of primarily the Anglo-Saxon world, turned toward defining the need to make society resilient to such threats. This materialized in policies such as the U.S. National Strategy for Homeland Security in 2007, the United Kingdom's Strategic Framework on Community Resilience, and the Australian National Strategy for Disaster Resilience. What becomes interesting, for our analysis, is the political science critique toward these policy development processes being based on an inherently neo-liberalist ideology of governance, i.e., in a reductionist manner, subjectivizing the resilience of the society at the level of the individual actors (Joseph 2013a, $b$, Schmidt 2013, Whitham 2013). As the Secretary General for the Swedish Civil Contingencies Agency concluded: "Another driver is shrinking national budgets that make it impossible to allocate huge sums of money to prevent certain scenarios or substantially minimize risk" (Lindberg and Sundelius 2013:1298), and further: "The foundation of a resilient society is having prepared individuals, families and communities. Therefore, motivating a private will among individuals to make reasonable investments in selfpreparedness is a major public leadership challenge for the future" (Lindberg an Sundelius 2013:1307). Such statements seem to legitimize the critique arguing that even societal resilience policies tend to subjectivize the individual as the source of a resilient society.

\section{Cross-scale: social-ecological resilience}

Society and Ecology belongs, and is named in accordance with, to a field studying resilience at a fourth level; a level connecting the resilience of the social system with that of the ecological. Similarly to how Luthar and Ciccihetti have argued for multiple levels of social systems being needed to interpret the resilience of the individual subject, scholars of social ecology have studied the connection between the individual subject and the ecological context in which the subject is located. In a special issue entitled Resilience Through Multi-Scalar Collaboration, edited by Bruce Goldstein, several of the contributions emphasized the strength of multilevel social networks in coming up with innovations to foster multilevel changes from policy to practice (Booher and Innes 2010, Butler and Goldstein 2010, Moore and Westley 2011, Beilin et al. 2013).

Adger (2000) has problematized whether resilient ecosystems also enable resilient communities when such communities are dependent on the resources of the ecosystems for their livelihoods. Adger suggested that if we treat the ecosystem as something external to the social system rather than interwoven, then the notions of resilience and vulnerability "provide a bridge between the analysis of institutions and economies with the natural resources in which they ultimately depend" (Adger 2000:361). Using a governance perspective, Adger et al. (2005) also argued that adaptation across scales is problematic for several reasons, including the not well understood politics involved in the 
construction of scale. Similarly, Berkes (2006) highlighted the political relationships between scales.

On the more optimistic side, social-ecologists, and some health scientists, suggest that there are indeed factors of resilience that are common across scales, i.e., resilience as fractal, including learning networks across scales and social capital that allow autonomous action, diversity in terms of economics and skills, and leadership (Nelson et al. 2007, Berkes 2009, Buikstra et al. 2010).

Several analytical perspectives are suggested to connect the global levels of decision making to the resilience of the local levels, including transition theory (Jerneck and Olsson 2008, Wilson 2012), commons theory (Berkes 2006), and often multi theoretical and methodological approaches (Almedom and Glandon 2007, Kulig et al. 2008). Commenting on the wide range of approaches Ross and Berkes (2014) still argue that there is a need for more methods exploring the coupling between social and ecological dimensions. By introducing the heritage of the young field, i.e., resilience engineering, focused on studying the resilience of highrisk organizations, we will outline how such methodological approaches could find their analytical grounds in the ecological view of cognition. We will also further explore not only spatial but also temporal scales.

\section{MESO AS THE BRIDGE BETWEEN MICRO AND MACRO}

Just as Berkes and Ross (2013) did, we suggest that the resilient subject can be analytically studied within a model of complex adaptive systems, i.e., resilience as an emergent system property. Also similar to the social-ecological studies of resilience, we believe that the scales of micro and macro can be analytically bridged by considering the meso. Although social-ecologists have typically turned to the social community as target of such analysis, our outlined analytical framework finds its empirical grounds in studies of high-risk working environments, i.e., organizations. The study of resilient organizations is a new field of research, but embraces some classical ideas for how to study complex interactions without reverting to causal explanations at the human subject level.

\section{Distributed cognition}

Resilience engineering (Hollnagel et al. 2006a, Hollnagel 2008, 2011) has similarities to the social-ecological school of resilience, which may not seem evident at first glance. The defining scholars of resilience engineering, some 20 years before coining the notion, lay the basis for another paradigm in the safety sciences. The paradigm, called Joint Cognitive Systems Theory (JCS; Hollnagel and Woods 1983, 2005, Rasmussen et al. 1994, Woods and Hollnagel 2006), also coined 'the second cognitive revolution,' rests on the same cybernetic approach to human cognition as does the social-ecological field (Re and Macchi 2010). The studies of organizational safety can serve as an inspiration to the studies of human resilience at different spatial scales, by its holistic reconstruction of the notion of cognition as an emergent phenomenon in itself.

Questioning the information-processing paradigm of human cognition, JCS shows how what seem to be inherently reductionist notions, i.e., human cognition, meaning making, or sense making, can be redefined to consider emergent phenomena of local interactions. From the distributed cognition perspective, cognition emerges from the interactions and relationships between local actors. Followers of this perspective typically argued that the information-processing paradigm does not consider the context and joint interactions of human work. Instead of analyzing cognition as a property of the human mind, they argued that cognition must in fact be studied as a goal-driven process located at the level of the work being conducted, i.e., a shift from 'cognition in the mind' to 'cognition in the wild' (Hutchins 1995). The model of distributed cognition thereby also incorporates the openness of the cognitive system, as stressed in our model of resilience (Hutchins 1995). The unit of analysis is the functional level of the cognitive system analyzed, rather than a predefined spatial scale. For scholars of human resilience, the challenge becomes to construct resilience as the adaptive capacity at such a functional level, which potentially implies the need for new models.

\section{Models of joint cognitive activity}

In studying resilience as emerging from local interactions and relationships, there is a need for models embracing such joint cognitive activities; models that do not simply state that the micromodels apply to greater spatial scales. For scholars of the second cognitive revolution, such models include coordination (Klein et al. 2004), cybernetics-inspired control (Hollnagel and Woods 2005), and holistic analysis of cognitive working situations (Vicente 1999, Bisantz and Burns 2008).

The use of an analytical framework of coordination and control is a promising way to understand organizational performance in situations when the organization is stretched to the limits of its capability. Interest in how the ability to adapt to unexpected and escalating situations varies with different levels of experience in both the domain of working and that of crisis management. Studies have been conducted focusing on how teams reached different levels of control based on how they coordinated their actions (Bergström et al. 2010, Palmqvist et al. 2012). The notion of coordination provides an analytic language locating the target of analysis at the functional level of the system studied. It is operationalized as the result of different actors' ability to predict the behavior of each other, i.e., interpredictability, their common terminology, values and frameworks, i.e., common ground, their ways to exercise influence on each other, i.e., directability, together with their previous experiences, or assumptions, of working together, i.e., choreography (Klein et al. 2004). It has been suggested that the macro cognitive framework is a promising one, and in further studies the language of control has been operationalized to map and follow the performance of a crisis management team, again based on their collective rather than individual performances (Bergström et al. 2010, Palmqvist et al. 2012).

The cognitive models exemplify how performance at the meso level can be interpreted at the functional level of the system engaged in a particular activity, i.e., coping with a specific stressor or adversit), one which incorporates the epistemology of openness and emergence in studies of human interaction. The distributed cognition framework, incorporating the same theoretical heritage as human ecology, should serve as a good inspiration for future studies of meso-level, i.e., community, resilience. What is further required is an interpretation of the complexities of the context itself. 


\section{Short-term dynamics of the context}

Resilience studies are interested in the ability of a system to adapt to adverse conditions. In the organizational studies, there has been an increased focus on the dynamics of such adversity; a process labeled 'escalation'. According to Woods and Patterson (2001), the concept of escalation concerns a process of how situations move from canonical or textbook to nonroutine to exceptional. In that process, escalation captures a relationship. As problems cascade, they produce an escalation of cognitive and coordinative demands, which elucidate the penalties of poor support for work.

One field that experiences escalating situations on a regular basis is healthcare (Nemeth et al. 2011, Bergström 2012, Bergström et al 2012). Studying organizational behavior during escalating situations in labor care, i.e., how labor situations go from being normal, managed by a midwife alone to nonnormal through the intervention decision to call a doctor for additional help and action, to the ultimate crisis situation of delivering through an emergency Caesarean section, it has been concluded that organizational adaptation cannot be understood in analytical terms by separating the dynamics of the situation from the organizational response (Bergström et al. 2012). In fact, the seemingly simple transition from normal to nonnormal situation, i.e., a call for help, seems to be an interesting window of opportunity for studies of resilience, being an inherently social process involving power relations, professional identity, the reproduction of organizational structures, and accountability (Cuvelier and Falzon 2008, Bergström et al. 2012, Dekker et al. 2013)

Showing the intimate connection between contextual and social behavior, from the meso-perspective of understanding resilience, the system is not adapting 'to' the changing of a situation, as much as it is an inherent part of such dynamics. In the studies of labor care, it has been argued for "the need to see escalation as a social process - one constructed by those who can alter or improvise on on-going habitual practice sometimes even to the extent that it can throw normal practice into question" (Bergström et al. 2012:5). From a complexity perspective, one cannot separate the resilience of the organization from the dynamics of the situation; they are part of the same dynamics. Not only does this perspective include the openness, i.e., how any attempt to draw a boundary is an analytical sacrifice, of the resilient system, but thereby also an important connection between micro and macro spatial and temporal scales.

How does a crisis 'deform' traditional, habitual, even historically determined local clinical practice, especially the ones practiced across and between clinical specialties? Clinical practice of course is local, as are all responses to emergency situations. But how does local practice change when crises occur and escalate? It is this escalation, this shift in tempo, that sets off a crisis from normal events, and this qualitative change is central for us to understand if we are to build an "anatomy of escalation" (Bergström et al. 2012:5)

It seems that the focus on escalation is important not only for the understanding of contextual adaptation and change in the shortterm, but also for organizational configuration in more long-term processes.

\section{Long-term dynamics of the context}

Similar to the work of Wilson (2012) in the social-ecological field, some seminal case studies of the organizational sciences form a theory for how to understand the path dependency of meso-level systems. Vaughan's (1996) study of the organizational processes preceding the Challenger disaster is a great example of how to couple the understanding of microlevel work to both meso and macrolevel processes of organizational culture, production demands, and international prestige. Snook (2000) offers a similar, multilevel analysis of a friendly fire shoot-down of two U.S. Blackhawk helicopters in northern Iraq in 1994. Both studies show how microlevel behavior is adapted and fine-tuned in normal organizational processes of normalization and drift rather than in processes of violation or carelessness. Essentially the studies include not only the relationship between microlevel actor and meso-level context, but also the history of such relationships.

Based on this perspective, being resilient will be a process of identifying conflicting goals in a complex environment using "numerous indicators in a proactive fashion to probe a system's adaptive capacity before system-wide collapse results in disaster" (Dekker and Pruchnicki 2013:8). The proactive monitoring of arising goal conflicts is a central part of a meso-perspective to resilience, linking micro and macro behavior. However, it is one for which there is yet a need for case studies showing successful examples.

\section{The need for danger}

Human or societal resilience studies of organizational resilience take the dangers of the field as their starting point. The scientific community studying resilience at a meso level has yet to hold a critical discussion concerning the ethical implications of this type of starting point, such as the one offered by Evans and Reid (2013). It is interesting to note that when scholars of organizational resilience in high-risk systems make their assumptions that there is a link between system complexity, danger, and the need for resilient strategies, they typically do so by referencing Perrow (1984), who is highly skeptical toward the organizational ability to manage the dangers inherent in complex social-technical systems (Woods and Branlat 2011). At all spatial levels discussed, it seems that resilience scholars ultimately take an optimistic stance toward the human ability to thrive through danger by relying on adaptive resilient capacities. Indeed it seems that the resilient subject thrives on danger as well in the organizational sciences as Evans and Reid concluded in the case of the policy agendas for the macro perspective.

\section{CONCLUDING REMARKS}

Focusing on human resilience in the context of interconnected health and social systems calls for the need to incorporate a systems perspective. However, studies at spatial scales at both the human and societal levels seem prone to, in a reductionist manner, locate the subject of resilience at the level of the psychosocial individual. To solve this apparent conflict, we suggest that studies of human resilience, at a variety of spatial scales, can be further inspired and bridged by additional analytical tools through the study of resilience at the meso level. Meso-level studies of resilience seem to be able to incorporate holistic principles by embracing an ecological model of cognition and through in depth studies of the relationship between organization and crisis across spatial as well as temporal scales. 
Responses to this article can be read online at: http://www.ecologyandsociety.org/issues/responses. php/6956

\section{Acknowledgments:}

The ongoing research is funded by the Swedish Civil Contingencies Agency (MSB). We thank the two anonymous reviewers whose comments greatly improved the paper.

\section{LITERATURE CITED}

Adger, W. N. 2000. Social and ecological resilience: are they related? Progress in Human Geography 24(3):347-364. http://dx. doi.org/10.1191/030913200701540465

Adger, W. N., N. W. Arnell, and E. L. Tompkins. 2005. Successful adaptation to climate change across scales. Global Environmental Change 15(2):77-86. http://dx.doi.org/10.1016/j.gloenvcha.2004.12.005

Alexander, D. E. 2013. Resilience and disaster risk reduction: an etymological journey. Natural Hazards and Earth System Sciences. 1:1257-1284. http://dx.doi.org/10.5194/nhessd-1-1257-2013

Allmark, P., S. Bhanbhro, and T. Chrisp. 2014. An argument against the focus on community resilience in public health. $B M C$ Public Health 14:62. http://dx.doi.org/10.1186/1471-2458-14-62

Almedom, A. M. 2004. Factors that mitigate war-induced anxiety and mental distress. Journal of Biosocial Science. 36(4):445-461. http://dx.doi.org/10.1017/S0021932004006637

Almedom, A. M., and D. Glandon. 2007. Resilience is not the absence of PTSD any more than health is the absence of disease. Journal of Loss and Trauma 12(2):127-143. http://dx.doi. org/10.1080/15325020600945962

Aranda, K., and A. Jones. 2010. Dignity in health-care: a critical exploration using feminism and theories of recognition. Nursing Inquiry 17(3):248-256. http://dx.doi.org/10.1111/j.1440-1800.2010.00494. $\underline{x}$

Aranda, K., L. Zeeman, J. Scholes, and A. S.-M. Morales. 2012. The resilient subject: exploring subjectivity, identity and the body in narratives of resilience. Health 16(5):548-563. http://dx.doi. org/10.1177/1363459312438564

Becker, P., M. Abrahamsson, and H. Tehler. 2011. An emergent means to assurgent ends: community resilience for societal safety and sustainability. Pages 29-33 in Erik Hollnagel, Eric Rigaud, and Denis Besnard, editors. Proceedings of the fourth resilience engineering symposium. Presses des MINES, Paris, France.

Beilin, R., N. T. Reichelt, B. J. King, A. Long, and S. Cam. 2013. Transition landscapes and social networks: examining on-ground community resilience and its implications for policy settings in multiscalar systems. Ecology and Society 18(2): 30. http://dx.doi. org/10.5751/ES-05360-180230

Bergström, J. 2012. Escalation: explorative studies of high-risk situations from the theoretical perspectives of complexity and joint cognitive systems. Dissertation. Lund University, Lund, Sweden. [online] URL: https://lup.lub.lu.se/luur/download?func= downloadFile\&recordOId $=2540835 \&$ fileOId $=2540838$
Bergström, J., N. Dahlström, E. Henriqson, and S. Dekker. 2010. Team coordination in escalating situations: an empirical study using mid-fidelity simulation. Journal of Contingencies and Crisis Management 18(4):220-230. http://dx.doi.org/10.1111/ j.1468-5973.2010.00618.x

Bergström, J., S. Dekker, J. M. Nyce, and I. Amer-Wåhlin. 2012. The social process of escalation: a promising focus for crisis management research. BMC Health Services Research 12(1):161. http://dx.doi.org/10.1186/1472-6963-12-161

Berkes, F. 2006. From community-based resource management to complex systems: the scale issue and marine commons. Ecology and Society 11(1): 45. [online] URL: http://www.ecologyandsociety. org/vol11/iss1/art45/

Berkes, F. 2009. Evolution of co-management: role of knowledge generation, bridging organizations and social learning. Journal of Environmental Management 90(5):1692-1702. http://dx.doi. org/10.1016/j.jenvman.2008.12.001

Berkes, F., and H. Ross. 2013. Community resilience: toward an integrated approach. Society and Natural Resources 26(1):5-20. http://dx.doi.org/10.1080/08941920.2012.736605

Bisantz, A. M., and C. M. Burns. 2008. Applications of cognitive work analysis. CRC, Boca Raton, Florida, USA. http://dx.doi. org/10.1201/9781420063059

Booher, D. E., and J. E. Innes. 2010. Governance for resilience: CALFED as a complex adaptive network for resource management. Ecology and Society 15(3): 35. [online] URL: $\underline{\text { http:// }}$ www.ecologyandsociety.org/vol15/iss3/art35/

Buikstra, E., H. Ross, C. A. King, P. G. Baker, D. Hegney, K. McLachlan, and C. Rogers-Clark. 2010. The components of resilience: perceptions of an Australian rural community. Journal of Community Psychology 38(8):975-991. http://dx.doi. org/10.1002/jcop.20409

Butler, J. 2004. Undoing gender. Routledge, London, U.K.

Butler, W. H., and B. E. Goldstein. 2010. The US fire learning network: springing a rigidity trap through multiscalar collaborative networks. Ecology and Society 15(3): 21. [online] URL: http://www.ecologyandsociety.org/vol15/iss3/art21/

Carmeli, A., Y. Friedman, and A. Tishler. 2013. Cultivating a resilient top management team: the importance of relational connections and strategic decision comprehensiveness. Safety Science 51(1):148-159. http://dx.doi.org/10.1016/j.ssci.2012.06.002

Cilliers, P. 1998. Complexity and postmodernism: understanding complex systems. Routledge, London, UK.

Cilliers, P. 2005. Complexity, deconstruction and relativism. Theory, Culture and Society 22(5):255-267. http://dx.doi. org/10.1177/0263276405058052

Cimellaro, G. P., D. Solari, C. S. Renschler, A. M. Reinhorn, and M. Bruneau. 2013. Community resilience index integrating network interdependencies. Pages 1789-1799 in B. J. Leshko and J. McHugh, editors. Structures congress 2013: bridging your passion with your profession. American Society of Civil Engineers, Reston, Virginia, USA. http://dx.doi.org/10.1061/9780784412848.157 
Costella, M. F., T. A. Saurin, and L. B. de Macedo Guimarães. 2009. A method for assessing health and safety management systems from the resilience engineering perspective. Safety Science 47(8):1056-1067. http://dx.doi.org/10.1016/j.ssci.2008.11.006

Cuvelier, L., and P. Falzon. 2008. Methodological issues in the quest for resilience factors. Pages 59-66 in E. Hollnagel, F. Pieri, and E. Rigaud, editors. Proceedings of the third symposium on resilience engineering. Presses des MINES, Paris, France.

Dekker, S. 2011. Drift into failure : from hunting broken components to understanding complex systems. Ashgate, Burlington, Vermont, USA.

Dekker, S., J. Bergström, I. Amer-Wåhlin, and P. Cilliers. 2013. Complicated, complex, and compliant: best practice in obstetrics. Cognition, Technology and Work 15(2):189-195. http://dx.doi. org/10.1007/s10111-011-0211-6

Dekker, S., and S. Pruchnicki. 2013. Drifting into failure: theorising the dynamics of disaster incubation. Theoretical Issues in Ergonomics Science 1-11. http://dx.doi.org/10.1080/1463922X$\underline{.2013 .856495}$

Evans, B., and J. Reid. 2013. Dangerously exposed: the life and death of the resilient subject, Resilience 1(2):83-98. http://dx.doi. org/10.1080/21693293.2013.770703

Gibbs, L., E. Waters, R. A. Bryant, P. Pattison, D. Lusher, L. Harms, J. Richardson, C. Macdougall, K. Block, E. Snowdon, H. C. Gallagher, V. Sinnott, G. Ireton, and D. Forbes. 2013. Beyond bushfires: community, resilience and recovery - a longitudinal mixed method study of the medium to long term impacts of bushfires on mental health and social connectedness, BMC Public Health 13(1):1036. http://dx.doi.org/10.1186/1471-2458-13-1036

Gomes, J. O., D. D. Woods, P. V. R. Carvalho, G. J. Huber, and M. R. S. Borges. 2009. Resilience and brittleness in the offshore helicopter transportation system: the identification of constraints and sacrifice decisions in pilots' work. Reliability Engineering and System Safety 94(2):311-319. http://dx.doi.org/10.1016/j.ress.2008.03.026

Grote, G., J. C. Weichbrodt, H. Günter, E. Zala-Mezö, and B. Künzle. 2009. Coordination in high-risk organizations: the need for flexible routines. Cognition, Technology and Work 11(1):17-27. http://dx.doi.org/10.1007/s10111-008-0119-y

Gunderson, L. H., and C. S. Holling. 2002. Panarchy: understanding transformations in human and natural systems Island, Washington, D.C., USA.

Hamiel, D., L. Wolmer, S. Spirman, and N. Laor. 2013. Comprehensive child-oriented preventive resilience program in Israel based on lessons learned from communities exposed to war, terrorism and disaster. Child and Youth Care Forum 42(4):261-274. http://dx.doi.org/10.1007/s10566-013-9200-7

Healy, S. 2003. Epistemological pluralism and the 'politics of choice.' Futures 35(7):689-701. http://dx.doi.org/10.1016/S0016-3287 (03)00022-3

Heylighen, F., P. Cilliers, P. and C. Gershenson. 2007. Complexity and philosophy. Pages 117-134 in J. Bogg and R. Geyer, editors. Complexity, science and society. Radcliffe, Oxford, UK.
Holling, C. S. 1973. Resilience and stability of ecological systems. Annual Review of Ecology, Evolution, and Systematics 4:1-23. http://dx.doi.org/10.1146/annurev.es.04.110173.000245

Hollnagel, E. 2006. Resilience - the challenge of the unstable. Pages 9-17 in E. Hollnagel, D. Woods and N. Leveson, editors. Resilience engineering: concepts and precepts. Ashgate, Burlington, Vermont, USA.

Hollnagel, E. 2008. Prologue: the scope of resilience engineering. Pages xxxix-xxxix in E. Hollnagel, J. Pariès, D. Woods, and J. Wreathall, editors. Resilience engineering in practice: a guidebook. Ashgate, Burlington, Vermont, USA.

Hollnagel, E. 2009. The ETTO principle: efficiency-thoroughness trade-off: why things that go right sometimes go wrong. Ashgate, Burlington, Vermont, USA.

Hollnagel, E. 2011. Resilience engineering in practice: a guidebook. Ashgate, Burlington, Vermont, USA.

Hollnagel, E., C. P. Nemeth, and S. Dekker. 2008. Resilience engineering perspectives, remaining sensitive to the possibility of failure. Ashgate, Burlington, Vermont, USA.

Hollnagel, E., and D. D. Woods. 1983. Cognitive systems engineering: new wine in new bottles. International Journal of Man-Machine studies 18:583-600.

Hollnagel, E., and D. D. Woods. 2005. Joint cognitive systems: foundations of cognitive systems engineering. CRC, Boca Raton, Florida, USA. http://dx.doi.org/10.1201/9781420038194

Hollnagel, E., D. Woods, and N. Leveson. 2006a. Resilience engineering: concepts and precepts. Ashgate, Burlington, Vermont, USA.

Hollnagel, E., D. D. Woods, and N. Leveson. 2006b. Prologue: resilience engineering concepts. Pages 1-6 in E. Hollnagel, D. D. Woods, and N. Leveson, editors. Resilience engineering: concepts and precepts, Ashgate, Burlington, Vermont, USA.

Hutchins, E. 1995. Cognition in the wild. MIT Press, Cambridge, Massachusetts, USA.

Jerneck, A., and L. Olsson. 2008. Adaptation and the poor: development, resilience and transition. Climate Policy 8 (2):170-182. http://dx.doi.org/10.3763/cpol.2007.0434.8.2.170

Johnsen, S. O., and M. Veen. 2013. Risk assessment and resilience of critical communication infrastructure in railways. Cognition, Technology and Work 15(1):95-107. http://dx.doi.org/10.1007/ s10111-011-0187-2

Joseph, J. 2013a. Resilience as embedded neoliberalism: a governmentality approach. Resilience 1(1):38-52. http://dx.doi. org/10.1080/21693293.2013.765741

Joseph, J. 2013b. Resilience in UK and French security strategy: an Anglo-Saxon bias? Politics 33(4):253-264. http://dx.doi. org/10.1111/1467-9256.12010

Klein, G., P. J. Feltovich, J. M. Bradshaw, and D. D. Woods. 2004. Common ground and coordination in joint activity. Pages 139-184 in W. B. Rouse and K. R. Boff, editors. Organizational simulation. John Wiley and Sons, Hoboken, New Jersey, USA. http://dx.doi. org/10.1002/0471739448.ch6 
Kolar, K. 2011. Resilience: revisiting the concept and its utility for social research. International Journal of Mental Health and Addiction 9(4):421-433. http://dx.doi.org/10.1007/s11469-011-9329-2

Kulig, J. C., D. Edge, and B. Joyce. 2008. Understanding community resiliency in rural communities through multimethod research. Journal of rural and Community Development 3(3):77-94. [online] URL: https://www.uleth.ca/dspace/bitstream/handle/10133/1265/ Community $\% 20$ Resiliency.pdf?sequence $=1$

Lindberg, H., and B. Sundelius. 2013. Whole of society disaster resilience: the Swedish way. Pages 1295-1319 in D. Kamien, editor. The McGraw-Hill homeland security handbook: strategic guidance for a coordinated approach to effective security and emergency management. McGraw-Hill, New York, New York, USA.

Luthar, S. S., and D. Cicchetti. 2000. The construct of resilience: implications for interventions and social policies. Development and Psychopathology 12(4):857-885. http://dx.doi.org/10.1017/ $\underline{\mathrm{S} 0954579400004156}$

McDaniels, T., S. Chang, D. Cole, J. Mikawoz, and H. Longstaff. 2008. Fostering resilience to extreme events within infrastructure systems: characterizing decision contexts for mitigation and adaptation. Global Environmental Change 18(2)-310-318. http:// dx.doi.org/10.1016/j.gloenvcha.2008.03.001

Miller, A., and Y. Xiao. 2007. Multi-level strategies to achieve resilience for an organisation operating at capacity: a case study at a trauma centre. Cognition, Technology and Work 9(2):51-66. http://dx.doi.org/10.1007/s10111-006-0041-0

Moore, M.-L., and F. Westley. 2011. Surmountable chasms: networks and social innovation for resilient systems. Ecology and Society 16(1): 5. [online] URL: http://www.ecologyandsociety. org/vol16/iss 1/art5/

Morel, G., R. Amalberti, and C. Chauvin. 2008. Articulating the differences between safety and resilience: the decision-making process of professional sea-fishing skippers. Human Factors 50 (1):1-16. http://dx.doi.org/10.1518/001872008X250683

Morel, G., R. Amalberti, and C. Chauvin. 2009. How good micro/ macro ergonomics may improve resilience, but not necessarily safety. Safety Science 47(2):285-294. http://dx.doi.org/10.1016/j. ssci.2008.03.002

Nelson, D. R., W. N. Adger, and K. Brown. 2007. Adaptation to environmental change: contributions of a resilience framework. Annual Review of Environment and Resources 32:395-419. http:// dx.doi.org/10.1146/annurev.energy.32.051807.090348

Nemeth, C. P., M. Nunnally, M. F. O’Connor, M. Brandwijk, J. Kowalsky, and R. I. Cook. 2007. Regularly irregular: how groups reconcile cross-cutting agendas and demand in healthcare. Cognition, Technology and Work 9(3):139-148. http://dx.doi. org/10.1007/s10111-006-0058-4

Nemeth, C., R. L. Wears, S. Patel, G. Rosen, and R. Cook. 2011. Resilience is not control: healthcare, crisis management, and ICT. Cognition, Technology and Work 13(3):189-202. http://dx.doi. org/10.1007/s10111-011-0174-7

Norris, F. H., S. P. Stevens, B. Pfefferbaum, K. F. Wyche, and R. L. Pfefferbaum. 2008. Community resilience as a metaphor, theory, set of capacities, and strategy for disaster readiness.
American Journal of Community Psychology 41(1-2):127-150. http://dx.doi.org/10.1007/s10464-007-9156-6

O’Sullivan, T. L., C. E. Kuziemsky, D. Toal-Sullivan, and W. Corneil. 2013. Unraveling the complexities of disaster management: a framework for critical social infrastructure to promote population health and resilience Social Science and Medicine 93:238-246. http://dx.doi.org/10.1016/j.socscimed.2012.07.040

Palmqvist, H., J. Bergström, and E. Henriqson. 2012. How to assess team performance in terms of control: a protocol based on cognitive systems engineering. Cognition, Technology and Work 14(4):337-353. http://dx.doi.org/10.1007/s10111-011-0183-6

Paltrinieri, N., K. Øien, and V. Cozzani. 2012. Assessment and comparison of two early warning indicator methods in the perspective of prevention of atypical accident scenarios. Reliability Engineering and System Safety 108:21-31. http://dx. doi.org/10.1016/j.ress.2012.06.017

Patterson, E. S., D. D. Woods, R. I. Cook, and M. L. Render. 2007. Collaborative cross-checking to enhance resilience. Cognition, Technology and Work 9(3):155-162. http://dx.doi. org/10.1007/s10111-006-0054-8

Perrow, C. 1984. Normal accidents: living with high-risk technologies. Basic Books, New York, New York, USA.

Rasmussen, J. 1997. Risk management in a dynamic society: a modelling problem. Safety Science 27(2-3):183-213. http://dx.doi. org/10.1016/S0925-7535(97)00052-0

Rasmussen, J., A. M. Pejtersen, and L. P. Goodstein. 1994. Cognitive systems engineering. Wiley, New York, New York, USA.

Re, A., and L. Macchi. 2010. From cognitive reliability to competence? An evolving approach to human factors and safety. Cognition, Technology and Work 12(2):79-85. http://dx.doi. org/10.1007/s10111-010-0148-1

Ross, A. J., J. E. Anderson, N. Kodate, K. Thompson, A. Cox, and R. Malik. 2014. Inpatient diabetes care: complexity, resilience and quality of care. Cognition, Technology and Work 16(1):91-102. http://dx.doi.org/10.1007/s10111-012-0247-2

Ross, H., and F. Berkes. 2014. Research approaches for understanding, enhancing, and monitoring community resilience. Society and Natural Resources 27(8):787-804. http://dx.doi. org/10.1080/08941920.2014.905668

Saurin, T. A., and G. C. Carim Júnior. 2011. Evaluation and improvement of a method for assessing HSMS from the resilience engineering perspective: a case study of an electricity distributor. Safety Science 49(2):355-368. http://dx.doi.org/10.1016/j.ssci.2010.09.017

Schmidt, J. 2013. The empirical falsity of the human subject: new materialism, climate change and the shared critique of artifice. Resilience 1(3):174-192. http://dx.doi.org/10.1080/21693293.2013.837241

Snook, S. A. 2000. Friendly fire: the accidental shootdown of U.S. Black Hawks over northern Iraq. Princeton University Press, Princeton, New Jersey, USA.

Ungar, M. 2005. Handbook for working with children and youth: pathways to resilience across cultures and contexts. Sage, Thousand Oaks, California, USA. 
Vaughan, D. 1996. The Challenger launch decision: risky technology, culture, and deviance at NASA. University of Chicago Press, Chicago, Illinois, USA.

Vicente, K. J. 1999. Cognitive work analysis: toward safe, productive, and healthy computer-based work. Lawrence Erlbaum Associates, Mahwah, New Jersey, USA.

Von Bertalanffy, L. 1950. An outline of general system theory. British Journal for the Philosophy of Science 1:134-165. http://dx. doi.org/10.1093/bjps/I.2.134

Walker, B., C. S. Holling, S. R. Carpenter, and A. Kinzig. 2004. Resilience, adaptability and transformability in social-ecological systems. Ecology and Society 9(2): 5. [online] URL: http://www. ecologyandsociety.org/vol9/iss2/art5/

Walker, J., and M. Cooper. 2011. Genealogies of resilience: from systems ecology to the political economy of crisis adaptation. Security Dialogue 42(2):143-160. http://dx.doi.org/10.1177/0967$\underline{010611399616}$

Whitham, B. 2013. From security to resilience? (Neo)liberalism, war and terror after 9/11. Resilience 1(3):219-229. http://dx.doi. org/10.1080/21693293.2013.842345

Wilson, G. A. 2012. Community resilience, globalization, and transitional pathways of decision-making. Geoforum 43 (6):1218-1231. http://dx.doi.org/10.1016/j.geoforum.2012.03.008

Woods, D. D., and M. Branlat. 2011. Basic patterns in how adaptive systems fail. Pages 127-143 in E. Hollnagel, J. Pariès, D. D. Woods, and J. Wrethall, editors. Resilience engineering in practice: a guidebook. Ashgate, Burlington, Vermont, USA.

Woods, D. D., and E. Hollnagel. 2006. Joint cognitive systems: patterns in cognitive systems engineering. Ashgate, Burlington, Vermont, USA. http://dx.doi.org/10.1201/9781420005684

Woods, D. D., and E. S. Patterson. 2001. How unexpected events produce an escalation of cognitive and coordinative demands. Pages 290-304 in P. A. Hancock and P. A. Desmond, editors. Stress, workload, and fatigue. Lawrence Erlbaum, Hillsdale, New Jersey, USA. [online] URL: http://csel.eng.ohio-state.edu/ productions/laws/laws talk/media/2 4 escalation.pdf

Woods, D. D., and J. Wrethall. 2008. Stress-strain plots as a basis for assessing system resilience. Pages 143-158 in E. Hollnagel, C. P. Nemeth, and S. W. A. Dekker, editors. Resilience engineering perspectives. Ashgate, Burlington, Vermont, USA. 